\title{
The effect of sputum smear grade on the anatomical position of lung involvement: A cross-sectional study
}

\author{
Razieh Behzadmehr ${ }^{1}$
}

\begin{abstract}
INTRODUCTION Tuberculosis is a chronic bacterial disease which is caused by mycobacterium and in most cases by mycobacterium tuberculosis. Chest radiography is one of the most basic diagnostic tools in the initial evaluation of the patient for further evaluation and progression of the disease. Hence, this study was performed to investigate the effect of grade smear on the involvement of different lung zones in chest radiography of patients with pulmonary tuberculosis referred to the Zabol tuberculosis center.

METHODS A descriptive-analytical study was conducted on all patients with pulmonary tuberculosis referred to the Zabol tuberculosis center in 2020, except patients with immunodeficiency - hepatitis and diabetes. Patients with smear grading who did not have chest radiography were excluded.

RESULTS The frequency of women in patients with grade 1, 2 and 3 were $73.3 \%, 50 \%$ and $70.6 \%$, respectively, and the frequency of men in grade 1 , 2 and 3 were 25.7\%, 50\% and 29.4\%, respectively. There was a significant difference between these two groups. Gender did not show significant difference in terms of smear grade $(p=0.192)$. The frequency of right or left lung involvement or both lungs in patients with grade 1,2 and 3 was not statistically significant $(p=0.306)$.
\end{abstract}

CONCLUSIONS It seems that there is no relationship between the smear grade and the involvement of different zones in the graph.

\begin{abstract}
AFFILIATION
1 Department of Radiology, Zabol University of Medical Sciences, Zabol, Iran

\section{CORRESPONDENCE TO}

Razieh Behzadmehr. Department of Radiology, Zabol University of Medical Sciences, Zabol, Iran. E-mail: razbebehzadmehr@gmail.com
\end{abstract}

\section{KEYWORDS \\ tuberculosis, lung, radiography, cross- sectional studies}

Received: 29 April 2021

Revised: 14 July 2021

Accepted: 30 July 2021

\section{INTRODUCTION}

Tuberculosis is a chronic bacterial disease which is caused by a collection of mycobacteria and in most cases by mycobacterium tuberculosis. More than 90\% of cases and deaths from tuberculosis occur in developing countries, countries where $75 \%$ of the cases occur, in the most economically active age group (15-54 years) ${ }^{1}$. In these countries, an adult with tuberculosis is not able to work for an average of 3 to 4 months, and therefore lowers by 20$30 \%$ his family's annual income, while the death of such a person is equal to on average 15 years of family income. It is clear that tuberculosis, in addition to the economic burden, has other indirect negative effects on the quality of life of patients or their families. On the other hand, multidrug resistance, which is the result of poor management of TB treatment, is a serious and growing problem in many countries of the world ${ }^{2}$. After the initial infection, $90 \%$ of people with healthy immunity prevent further proliferation of TB bacilli, causing it to enter the latent phase. The remaining 10\% develop tuberculous pneumonia with lymphatic spread at the site of primary implantation or near the umbilical cord, and may present with umbilical lymphadenopathy or with disease in distant sites such as cervical lymphadenopathy, meningitis, pericarditis, or millet distribution ${ }^{3}$.

The basis of the diagnosis of pulmonary tuberculosis is a direct and simple test of patients' sputum. In the best case scenario, the susceptibility of the patients' sputum test is examined. Chest radiography should be used as one of the most basic diagnostic tools in the initial evaluation of the patient for further evaluation and progression of the disease. Chest radiography is a suitable and sensitive tool for diagnosing lung damage, including tuberculosis, so that in case of normal chest X-ray, tuberculosis diagnosis is removed. On the other hand, in cases where we are actively looking for this disease and when it is diagnosed in its early stages, pulmonary involvement and the chance of transmission to others is low. The type and extent of pulmonary involvement can indicate the degree of success in early detection of this disease. Therefore, this study aimed to evaluate the effect of smear grade on involvement of different lung zones in chest radiography of patients with pulmonary tuberculosis referred to the TB center Zabol.

\section{METHODS}

A descriptive-analytical study was conducted on all patients with pulmonary tuberculosis referred to the Zabol Tuberculosis Center in 2020, except for patients with immunodeficiency - hepatitis and diabetes. In this study, 101 patients were studied, of which 71 were female and 30 were male. Samples were recorded according to a checklist that included demographic information, sputum smear grade, and radiographic findings of the chest. Demographic information 
of patients such as age, sex and place of residence as well as smear information and its grade and chest radiographic findings were collected. Data were collected using SPSS software in the form of frequency, percentage, mean and standard deviation and the data were analyzed using chisquared test.

\section{RESULTS}

Of the 101 participants, 71 (70.3\%) were male and the rest were female. The mean age of patients was 62.68 years with a standard deviation of 13.61. The youngest and oldest patients were aged 18 and 86 years, respectively. There was

Table 1. Gender distribution of patients according to smear grading

\begin{tabular}{|l|c|c|c|c|}
\multirow{2}{*}{ Sex } & \multicolumn{3}{|c|}{ Smear grading } & \multirow{2}{*}{ p } \\
\cline { 2 - 4 } & $\begin{array}{c}\text { Grade 1 } \\
\text { n (\%) }\end{array}$ & $\begin{array}{c}\text { Grade 2 } \\
\text { n (\%) }\end{array}$ & $\begin{array}{c}\text { Grade 3 } \\
\text { n (\%) }\end{array}$ & \\
Male & $18(25.7)$ & $7(50.0)$ & $5(29.4)$ & 0.192 \\
Female & $52(73.3)$ & $7(50.0)$ & $12(70.6)$ &
\end{tabular}

Table 2. Frequency of involvement of different zones of the lung according to smear grading

\begin{tabular}{|c|c|c|c|c|}
\hline \multirow[t]{2}{*}{ Zone } & \multicolumn{3}{|c|}{ Smear grading } & \multirow[t]{2}{*}{$\mathbf{p}$} \\
\hline & $\begin{array}{c}\text { Grade } 1 \\
\text { n (\%) }\end{array}$ & $\begin{array}{c}\text { Grade } 2 \\
\text { n (\%) }\end{array}$ & $\begin{array}{c}\text { Grade } 3 \\
\text { n (\%) }\end{array}$ & \\
\hline Nothing & $\mathrm{O}(0.0)$ & $0(0.0)$ & $2(2.8)$ & \multirow{8}{*}{0.337} \\
\hline Upper & $1(5.8)$ & $1(7.1)$ & $13(18.5)$ & \\
\hline Middle & $1(5.8)$ & $0(0.0)$ & $13(18.5)$ & \\
\hline Lower & 5 (29.4) & $4(28.5)$ & $18(25.7)$ & \\
\hline Upper and Middle & $4(23.5)$ & $1(7.1)$ & $4(5.7)$ & \\
\hline Upper and Lower & $3(17.6)$ & $3(21.4)$ & $8(11.4)$ & \\
\hline $\begin{array}{l}\text { Middle and } \\
\text { Lower }\end{array}$ & $1(5.8)$ & $3(21.4)$ & 7 (10.0) & \\
\hline $\begin{array}{l}\text { Upper and } \\
\text { Middle and } \\
\text { Lower }\end{array}$ & $3(17.6)$ & $3(21.4)$ & 8 (11.4) & \\
\hline
\end{tabular}

Table 3. Frequency of smear grading by lung involved

\begin{tabular}{|l|c|c|c|c|}
\hline \multirow{2}{*}{ Lung } & \multicolumn{3}{|c|}{ Smear grading } & \multirow{2}{*}{ P } \\
\cline { 1 - 4 } & $\begin{array}{c}\text { Grade 1 } \\
\text { n (\%) }\end{array}$ & $\begin{array}{c}\text { Grade 2 } \\
\text { n (\%) }\end{array}$ & $\begin{array}{c}\text { Grade 3 } \\
\text { n (\%) }\end{array}$ & \\
\cline { 1 - 4 } Nothing & $2(2.8)$ & $0(0.0)$ & $0(0.0)$ & \\
Right & $31(44.3)$ & $3(21.4)$ & $4(23.5)$ & 0.306 \\
Left & $13(18.6)$ & $2(14.3)$ & $5(29.4)$ & \\
Right and Left & $24(34.3)$ & $9(64.3)$ & $8(47.0)$ &
\end{tabular}

no statistically significant difference between the two sexes in terms of smear grade $(p=0.192)$ (Table 1$)$.

Table 2 shows that the frequency of involvement of different lung zones in grade 1,2 and 3 was not statistically significantly different $(p=0.337)$.

Table 3 shows that the frequency of right or left lung involvement or both lungs in patients with grade 1,2 and 3 was not statistically significant $(p=0.306)$.

\section{DISCUSSION}

There is no study on the relationship between the degree of positivity of primary smear and chest radiographic findings of patients in Iran and in the world; few studies have been conducted in this regard and due to the importance of this issue in timely diagnosis and reduction of infection and treatment of the disease, the present study was performed to determine the relationship between smear grading and chest radiographic findings in patients referred to the Zabol Tuberculosis Center in 2015-2016. In this study, 101 patients with tuberculosis were studied. Of these, 71 (70.3\%) were female and the rest were male. In the studied patients, 70 cases had grade 1 ( $74.3 \%$ female and $25.7 \%$ male), 14 cases had grade 2 (50\% female and 50\% male) and 17 cases had grade 3 (70.6\% female and $35.7 \%$ male). As a result, there was no significant difference between the two sexes in terms of smear grade $(p=0.192)$. Due to the lack of similar studies that have examined the relationship between sex and smear grading, the findings of this study cannot be compared with other. The mean age of patients was 62.68 years with a standard deviation of 13.61. The youngest and oldest patients were aged 18 and 86 years, respectively. The mean age of patients with grade 1,2 and 3 was 64.47 , 62.07 and 55.82 years, respectively. The age difference between patients in different grades was not statistically significant $(p=0.122)$. There was also no relationship between increasing or decreasing age and smear grading. In other studies, children under 15 years old were in the study group and therefore due to differences in the study population it is not possible to compare the results ${ }^{4-6}$. Most patients were from Zabol city (52.5\%) and the least were from Hamoon and Helmand cities (2\%). The frequency of lower lobe involvement was higher in all three grades and its percentage was slightly higher in grade 3 . But in general, the frequency of involvement of different lung zones in grade 1, 2 and 3 was not significantly different $(p=0.337)$. As a result, there seems to be no relationship between the smear grade and the involvement of different zones in the graph. This finding is not consistent with other studies. In the study of Gopi et al. ${ }^{7}$, with increasing smear grade, the score of involvement of the upper lobe was significantly increased $(p=0.0001)$.

In the Kanade et al. ${ }^{8}$ study, with increasing the smear grade, the score of involvement in the central lobe increased significantly ( $p=0.0001)$, which can be attributed to the high diagnostic accuracy of HRCT compared to CXR. Examination of the right or left lung or both showed that in grade 1 and 2 
the right lung and in grade 3 the left lung were more involved, and the involvement of both lungs in grade 2 was more than in grade 1 and 3 (63\%, 47\% and 32\%, respectively). Left or both lungs were not statistically significant in patients with grade 1,2 and 3 ( $p=0.306)$, so no correlation was observed with the smear grade.

\section{Limitations}

Due to the lack of similar studies examining CXR findings based on smear grading, it was not possible to compare the study findings with other studies.

\section{CONCLUSIONS}

The present study demonstrated the importance of further studies examining CXR findings based on smear grading. This study can be used as a basis for such studies.

\section{CONFLICTS OF INTEREST}

The authors have completed and submitted the ICMJE Form for Disclosure of Potential Conflicts of Interest and none was reported.

\section{FUNDING}

There was no source of funding for this research.

\section{ETHICAL APPROVAL AND INFORMED CONSENT}

The study was conducted in accordance with the institutional and national research committee standards (ethical approval number: IR.ZBMU.1.REC.1396.2), and with the WMA Declaration Of Helsinki for Medical Research Involving Human Subjects. Informed consent was received from all participants.

\section{DATA AVAILABILITY}

The data supporting this research are available from the author on reasonable request.

\section{PROVENANCE AND PEER REVIEW}

Not commissioned; externally peer reviewed.

\section{REFERENCES}

1. World Health Organization. Global Tuberculosis Control: A short update to the 2009 report. World Health Organization; 2009. Accessed July 14, 2021. http://apps.who.int/iris/ bitstream/handle/10665/44241/9789241598866_eng. pdf;jsessionid $=682 \mathrm{CADCCD38653C8F4BCDB7A9ECB6C58?}$ sequence $=1$

2. World Health Organization. Treatment of tuberculosis: guidelines. World Health Organization; 2010. Accessed July 14, 2021. https://apps.who.int/iris/bitstream/ handle/10665/44165/9789241547833_eng.pdf

3. World Health Organization. Global tuberculosis control: WHO report 2010. World Health Organization; 2010.
Accessed July 14, 2021. https://apps.who.int/iris/ bitstream/handle/10665/44425/9789241564069_eng. pdf.? sequence $=1$

4. Tavakoli A. Incidence and Prevalence of Tuberculosis in Iran and Neighboring Countries. Zahedan J Res Med Sci. 2017;19(7):e9238. doi:10.5812/zjrms.9238

5. Motamedizadeh F, Alimohammadzadeh K, Hosseini SM. Monitoring and evaluation of program performance and management control system of tuberculosis: A ten-year cross-sectional study in Sistan and Baluchestan province, Iran. Article in Persian. Shiraz E-Medical Journal. 2018;19(9).

6. Nasiri MJ, Heidary M, Goudarzi H, Tabarsi P. Trends in multidrug-resistant tuberculosis in Tehran, Iran: an analysis of published data. GMS Hyg Infect Control. 2019;14:11. doi:10.3205/dgkh000327

7. Gopi PG, Chandrasekaran V, Subramani R, et al. Association of conversion \& cure with initial smear grading among new smear positive pulmonary tuberculosis patients treated with Category I regimen. Indian J Med Res. 2006;123(6):807814. Accessed July 14, 2021. https://core.ac.uk/download/ pdf/83048919.pdf

8. Kanade SR, Nataraj G, Anita R, Mehta PR. Correlation between Smear Positivity Grade at Two Months with Culture Positivity and Final Outcome in Patient Receiving Anti Tuberculosis Treatment. Bombay Hosp J. 2010;52(2):183-188. Accessed July 14, 2021. https://www.bhj.org.in/journal/2010-5202april/download/pg183-188.pdf 